Sattoe, J.N.T. 'Skills for growing up': supporting autonomy in young people with kidney disease. Journal of Renal Care: 2014, 40(2), 131-139

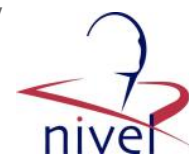

\begin{tabular}{|l|l|}
\hline $\begin{array}{l}\text { Postprint } \\
\text { Version }\end{array}$ & 1.0 \\
\hline Journal website & $\begin{array}{c}\text { http://onlinelibrary.wiley.com/doi/10.1002/jorc. 12046/abstract;jsessionid=B0279A } \\
\text { 685EA169E4B7BB37256C66F9D3.f02t04 }\end{array}$ \\
\hline Pubmed link & https://www.ncbi.nlm.nih.gov/pubmed/24373148 \\
\hline DOI & 10.1002/jorc.12046 \\
\hline
\end{tabular}

This is a NIVEL certified Post Print, more info at http://www.nivel.eu

\title{
'Skills for growing up': supporting autonomy in young people with kidney disease
}

\author{
SUMMARY \\ Background and Objectives: End-stage kidney disease (ESKD) may interfere \\ with children's developmental task of acquiring autonomy and participation. The \\ Skills for Growing Up tool encourages normal development towards \\ independence and autonomy during paediatric rehabilitation. This study aimed \\ to adapt this self-management tool for use in paediatric nephrology, and to test \\ whether its use is feasible in daily practice. \\ Design and Participants: A Delphi study was conducted among patients, their \\ parents, professionals and experts to adjust the tool for use in nephrology. \\ Feasibility was studied through individual and group interviews with \\ professionals in all Dutch paediatric nephrology centres. \\ Results: Agreement was reached on the areas of social participation and medical \\ management of ESKD. Compared with the original, the new instrument holds \\ considerable more attention for autonomy in the renal healthcare area; for \\ example, dealing with medication and transplantation. Professionals used and \\ appreciated the tool, but the paper form was seen to limit feasibility. \\ Conclusions: Making the tool available online is important. The challenge for \\ professionals is to move beyond the focus on medical management and to \\ consider developmental tasks when coaching their patients into adulthood. \\ Application to Practice: The Skills for Growing Up-Nephrology (SGU-N) tool \\ is a promising instrument for use by professionals in paediatric nephrology. Its \\ use can help young people achieving autonomy and may contribute to their \\ successful transition to adulthood and adult care.
}

\section{INTRODUCTION}

A chronic medical condition may interfere with the main developmental task of acquiring autonomy and participation (Meijer et al. 2002; Turkel \& Pao 2007). Young people with end-stage kidney disease (ESKD) often achieve fewer developmental milestones or lag behind in development, compared with healthy peers and peers with other chronic conditions (Stam et al. 2006). They are at risk for cognitive impairment, low educational attainment and psychosocial and psychiatric problems (Grootenhuis et al. 2006; Icard et al. 2008). Young adults who reached fewer developmental milestones in adolescence experience greater impact of their condition on their daily lives (Grootenhuis et al. 2006). As sound psychosocial development in early life relates to successful participation (Maurice-Stam et al. 2011; Haverman et al. 2012), it seems valuable to help young people to achieve psychosocial milestones (Verhoof et al. 2011). 
Sattoe, J.N.T. 'Skills for growing up': supporting autonomy in young people with kidney disease. Journal of Renal Care: 2014, 40(2), 131-139

The Holland Bloorview Kids Rehabilitation Hospital in Toronto developed the Skills for Growing Up (SGU) tool (Guidelines for Service Providers, 2007). An authorised Dutch adaptation appeared feasible in rehabilitation practice (Maathuis et al. 2012). The SGU encourages typical development towards independence and autonomy in nine life areas: 'me', 'health care', 'relationships', 'education', 'work', 'living and ADL (activities of daily living)', 'transportation', 'leisure activities' and 'sports'. It consists of three age-appropriate checklists (7-11 years: 'Getting started'; 12-16 years: 'On my way'; 17 years and older: 'Almost there').

Apart from the tasks young people with chronic conditions have in common (van Staa et al. 2011a) those with ESKD face disease-specific challenges (e.g. medication/diet adherence, reductions in fluid allowance, dialysis or transplantation), stressing the need for an adaption of the SGU for paediatric nephrology. Also, as it is most likely to be used in a hospital setting, its feasibility for the hospital staff is important. This study aimed to adapt the SGU for use in paediatric nephrology, and to test whether the use of the tool is feasible in paediatric kidney care.

\section{PATIENTS AND METHODS}

\section{The Skills for Growing Up Tool (SGU)}

- The SGU is built on four key principles:

- Universality, meaning that the content encourages family interaction about normal development (i.e. making choices/participating in life).

- Family centeredness reflected by the way in which young people and their families identify items they want to work on and set goals.

- Shared management (Kieckhefer 2002; Gall et al. 2006): a conceptual approach for the transition to adulthood.

- Developmental approach: independence increases by developmentally appropriate steps in knowledge and competencies regarding self-reliance and autonomy in the nine life areas. Therefore, developmental age determines which list is appropriate to use.

Young people and their parents score the SGU's items in the appropriate checklist with 'yes' or 'no', depending on whether they perceive to have already acquired the skills or knowledge referred to. Next, they choose three items to work on for the next months, set goals to be achieved and draft an action plan on how to achieve these goals. The forms are completed at home, and the instruction for parents of children of 12 years or older is to let children fill out the form and make an action plan by themselves. In this way, young people would be allowed to address key adolescent health issues they might not want to share with their parents (e.g. substance use). Professionals may assist by addressing young people's independence during medical consultation (i.e. skills training or referral to other professionals). Examples of items and the action plan format are presented in Box $\underline{1}$.

\section{[BOX 1]}

\section{STUDY SAMPLES}

This study was conducted in three phases: adaptation of the SGU; pilot testing of the SGU for use in paediatric nephrology (SGU-N) and finalising the SGU-N.

All paediatric nephrology centres in the Netherlands participated. 
Sattoe, J.N.T. 'Skills for growing up': supporting autonomy in young people with kidney disease. Journal of Renal Care: 2014, 40(2), 131-139

The Medical Ethics Committee of the Erasmus MC University Medical Center approved all study procedures. Participants received information letters and informed consent forms through the contact persons in the centres. They were assured of confidentiality and data were processed anonymously. All participants gave informed consent. If children were younger than 16 years, parents gave informed consent. In case of adolescents of 16 years and older, both adolescents and parents filled out and signed the informed consent forms.

In the first phase, professionals were invited to participate in a Delphi study (Jones \& Hunter 1995). Each centre invited two parents and two young people with ESKD to participate. These young people and parents were unrelated, and received an information letter and were subsequently contacted via telephone. Four experts in the areas of nephrology and the development of autonomy and self-management in chronically ill were invited to participate in adapting and finalising the SGU-N (Phases 1 and 3).

In the second phase, each centre selected nine young people without severe learning disabilities, equally distributed over the three age groups, and their parents to participate in the pilot. These young people with ESKD all had an appointment scheduled for consultation within two months after the start of the pilot. In each centre, one professional who used the tool was interviewed.

\section{STUDY PROCEDURE}

\section{Phase 1: Adaptation Of The Sgu}

The Delphi study consisted of three rounds. Participants checked the relevance and phrasing of the original items and added nephrology-specific items (response categories: yes/no) (Round 1). To assess the extent of consensus participants assessed items' relevance on a seven-point Likert scale (Round 2). The experts reviewed the non-consensus items and decided on the definitive item-pool (Round $3)$.

\section{Phase 2: Pilot Of The Sgu-N}

The teams were trained in application of the tool. Next, the SGU-N was pilot tested in all centres for two months and individual and focus group interviews with professionals were conducted to assess feasibility. For both, interview guides were drafted. In the individual interviews, professionals reflected on their experiences with the SGU-N, its item-pool, and its potential impact on young people with ESKD and their families. The results were used to structure the focus group interviews, which primarily aimed at item reduction but also dealt with the format of the SGU-N and its value for nephrology practice.

\section{Phase 3: Finalising The Sgu-N}

The results of the group interviews and an additional expert meeting were used to finalise the SGU-N, to reduce the number of items and to underpin recommendations for its use in clinical practice. Professionals decided on the final healthcare item pool, and experts determined the final participation item pool.

\section{ANALYSES}

After Delphi Round 1, items were maintained for re-assessment in Round 2 if: $\geq 75 \%$ of the respondents marked the item as relevant without need for reformulation or 
Sattoe, J.N.T. 'Skills for growing up': supporting autonomy in young people with kidney disease. Journal of Renal Care: 2014, 40(2), 131-139

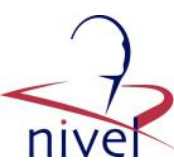

between $30 \%$ and $75 \%$ of the respondents marked the item as relevant but with need for reformulation.

Proposals for reformulations were reviewed by two researchers (J.N.T.S. and S.R.H.) independently and discussed and reformulated together.

After Round 2, item relevance and consensus among respondents were determined by a median item score $(\geq 6)$ and an interquartile range (IQR $\leq 2.0$ ), respectively. SPSS 17.0 was used for the statistical analyses. The pilot version of the SGU-N was then drafted. J.N.T.S. and S.R.H. independently scored the items of the pilot SGU-N with 'aimed at knowledge' or 'aimed at skills'. Cohen's kappa coefficient $(\kappa)$ determined inter-rater agreement.

The individual and group interviews were digitally recorded, transcribed ad verbatim and then imported into the qualitative software package Atlas.ti 6.2.27

(www.atlasti.com). Thematic analysis was applied (Creswell 2003). In Atlas.ti, initial codes (subthemes) were formulated on the basis of the interview guide and these were complemented with newly formed codes.

After the group interviews and expert meeting, the final SGU-N was developed. Again, J.N.T.S. and S.R.H. independently scored the nature of the items and Cohen's kappa coefficient was computed.

\section{RESULTS}

\section{Participants}

Twenty-six professionals, that is (specialised) nurses, social workers, nephrologists, psychologists, pedagogic workers and a dietitian, 10 adolescents with ESKD, 10 parents and 4 experts were invited to participate in the Delphi study. Thirty-eight of these ( 22 professionals, 7 adolescents, 6 parents, 3 experts) (76\%) participated in Round 1. Thirty-seven (20 professionals, 9 adolescents, 6 parents, 2 experts) (74\%) participated in Round 2 (Table 1). Finally, three experts ( $75 \%$ of all invited) participated in Round 3. One had expertise in care for chronically ill adolescents, one was involved in the development of the original SGU, and one was experienced in research in ESKD.

\section{[TABLE 1]}

Five professionals (one from each centre) were individually interviewed [a psychologist and four (specialised) nurses]. Four focus group interviews took place in four of the centres with all the professionals who participated in the Delphi study. In the fifth centre, one individual interview with a specialised nurse was held instead, because of time constraints.

\section{Adapting And Finalising The Sgu}

'Getting started' consisted of 41 original items, 36 were maintained and 18 were added (Round 1). Of the 54, 41 items were maintained (IQR $\leq 2$; median $\geq 6)(76 \%)$ (Round 2). Finally, the experts added seven items (Round 3); 37\% of the items addressed knowledge, while $65 \%$ covered skills $(\kappa=0.94)$. Of the 60 items of ' On my way', 53 were judged eligible and 35 items were added (Round 1); 5 of the 88 'On my way' items $(6 \%)$ were removed (IQR $>2$; median $<6$ ) (Round 2). Finally, the experts added eight items (Round 3); $47 \%$ of the items addressed knowledge and $43 \%$ skills $(\kappa=0.96)$. 'Almost there' contained 50 items of which 48 were judged eligible (Round 1); 31 items were added. None of the 79 items was removed (Round 
Sattoe, J.N.T. 'Skills for growing up': supporting autonomy in young people with kidney disease. Journal of Renal Care: 2014, 40(2), 131-139

2). Finally, the experts added four items (Round 3); $47 \%$ of the items addressed knowledge, while $53 \%$ addressed skills $(\kappa=0.88)$.

Since the pilot version of the SGU-N was considered to be too long for use in daily clinical practice, shortening was deemed necessary. The experts determined the core items in the participation areas, and group interviews with the teams were held to reduce the number of items in the healthcare area. The distribution of items within the SGU, the pilot SGU-N and the final SGU-N are presented in Table 2. The healthcare items in the SGU-N were divided into five categories: nutrition, symptoms and medication, visiting the hospital, dialysis and transplantation. In 'Getting started', 31\% of the items addressed knowledge, while $69 \%$ covered skills $(\kappa=1.0)$. In 'On my way', $42 \%$ considered knowledge and $58 \%$ skills $(\kappa=1.0)$. In 'Almost there', $45 \%$ of the items covered knowledge, while $55 \%$ addressed skills $(\kappa=0.91)$.

\section{[TABLE 2]}

\section{Pilot Testing}

\section{Sgu-N In Clinical Practice}

Nurses primarily introduced the SGU-N to young people with ESKD and their parents and worked with the tool in daily clinical practice. In one centre, a psychologist worked with the SGU-N during the pilot. The checklists and action plans were discussed with the young people and their parents and the outcomes were reported during multidisciplinary team meetings. If necessary, young people and their parents would be supported by other professionals in achieving their goals. We think that [working with the SGU-N] fits our job, because we form the pivot of the team. We [...] can ask other professionals for their input or support (Nurse). However, some items raised questions about the healthcare professional's role. They wondered if their supporting role indeed had to extend as far as the areas of living, transportation and me.

This boy formulated a goal in the area of living. He came up with it himself and his mother was very happy with it, so they are going to work on it now. However, I as a psychologist have nothing to do with that. Neither do our nurses or doctors (Psychologist).

Most participants filled out the checklists, but found it hard to formulate goals and working plans. The professionals thus ended up "screening the whole list", while paying attention to the items scored with 'no'. They tried to support the formulation of goals and plans. Professionals did not find this working method problematic, although it did cost extra time.

I don't expect [people not formulating goals and plans] to change in the future. It is something we have to support them in, which is absolutely no problem. (Nurse). Yet, it also worked this way if young people and their parents did make an action plan with goals.

What I eventually saw was the action plan, but I got curious and I asked if I could see the whole list. The mother and child were okay with this (Psychologist).

Most of the professionals reported that working with the SGU-N was time consuming for two reasons. Firstly, the SGU-N was too long.

The items. The areas. These are good. However, the list is too long. (Nurse). 
Sattoe, J.N.T. 'Skills for growing up': supporting autonomy in young people with kidney disease. Journal of Renal Care: 2014, 40(2), 131-139

The second reason was that professionals received the lists and plans at consultation and thus needed extra time during consultation to review these.

I think it could [save us time] if we would get an electronic version of the SGU-N.

(Nurse).

An electronic version of the SGU-N was highly preferred, also because it would give the possibility to send people an automatic reminder.

People often forget to bring [the list] with them. [...] If it's electronic, they could receive an automatic reminder (Nurse).

Furthermore, professionals thought an electronic version would help them to fully embed the SGU-N in their working routines, and that it could provide the additional benefit of integration with electronic patient files-leading to a better overview of the patient for the whole team. They shared the view that the SGU-N has potential for fitting well to their daily routine, but at the end of the pilot this had not yet been achieved.

\section{The Value Of The Sgu-N}

All nine life areas were considered relevant. The SGU-N gave professionals the opportunity to "systematically" address important issues, which was hardly done before. As such it provides healthcare professionals with

"guidance to support young people and their parents". "[It helps us to] concretize the attention for transition [to adult care and adulthood]" (Nurse). "It can act as a guideline. If you have to deal with a non-adherent patient, it helps you realize what steps you can take to withdraw the focus from the non-adherence, while at the same time reaching the subject" (Nurse).

Furthermore, professionals valued that the tool enabled them to focus on autonomy and self-management of patients at young age, and that it allowed for small steps in the development of independence. The family interaction that was stimulated by the tool was appreciated. Yet, they had to get used to the shift in focus of giving input to getting input from adolescents and their parents. Most professionals welcomed it, but some regretted that the SGU-N is not designed for "testing knowledge".

An important difference in view was that we wanted to see the SGU-N as a checklist to determine patients' progress. [...] We think this is a missed chance (Nurse).

Professionals received predominantly positive reactions from participants. Many parents said it was an 'eye-opener' and supported child-parent interaction.

Using the instrument creates an opportunity for parents and children to start a conversation (Nurse).

Professionals mentioned that the SGU-N could be particularly useful for those who have a difficult home situation (less social support), who find it difficult to start conversations on certain topics or who are overprotected by their family.

\section{DISCUSSION}

\section{The Sgu-N's Feasibility: Thwarting Logistical Problems}

The SGU was adapted for use in five paediatric nephrology centres in the Netherlands and the tool's feasibility was evaluated. All teams had implemented the SGU-N and appreciated the four key principles. The SGU-N was viewed as a valuable addition in care for young people with end-stage renal disease (ESRD), as is the original SGU in rehabilitation care. Nevertheless, the logistical problems 
associated with the paper version of the SGU-N formed a major interfering factor for good embedment in daily practice. This barrier might be overcome by integrating the SGU-N into the KLIK PROfile, which is an effective web-based application for the use of patient reported outcomes (Haverman et al. 2011, 2013). Electronic availability of the tool will add to user friendliness and facilitate healthcare professionals to incorporate the SGU-N into their consultations, contributing to the quality of holistic care for young people with ESRD.

\section{Healthcare Professionals: Moving Beyond Medical Management}

The need for a tool to support young people to develop self-management skills and become an autonomous individual is widely recognised (Newman et al. 2009; Annunziato et al. 2012). Interventions to enhance psychosocial functioning and social participation of young people with a chronic condition are considered an integral component of comprehensive care (Meijer et al. 2002; Martinez et al. 2011). Yet, professionals working in paediatric nephrology seem to have a strong focus on supporting patients' knowledge and skills in the healthcare area. Numbers of healthcare items in the SGU-N increased 1.5- to 2-fold compared with the original tool, and professionals wondered if their supporting role had to extend to specific topics in the participation areas. Self-management is often used as a synonym for self-care or therapeutic adherence (Koch et al. 2004) and is incorrectly assumed to serve the goal of maximising clinical outcomes and treatment efficacy in paediatric care (Lorig \& Holman 2003; Modi et al. 2012).

Self-management refers to "the individual's ability to manage the symptoms and the consequences of living with a chronic condition, including treatment, physical, social and lifestyle changes" (Barlow et al. 2002). In this broad view, it encompasses three elements: medical management (treatment/healthcare), role management (participation in society) and emotion management (emotional consequences of being ill) (Lorig \& Holman 2003). Research has shown that young people and adults with ESRD, who have to deal with dialysis or transplantation, need support on all three elements (McDonagh 2000; Groothoff et al. 2005; Jansen et al. 2010; Martinez et al. 2011). In a recent study, adults with chronic kidney disease prioritised research themes as 'mastery', 'partnership', 'responsibility', 'sexuality', 'work' and 'social contacts' for practically oriented research that induce support in dealing with their condition in daily life (Schipper \& Abma 2011). This contrasts to the dominant medical viewpoint that refers to the chronic condition as one's 'master status' (Goffman 1963). The ambiguity surrounding the term 'self-management' calls for more precise definitions of what is important for people with chronic conditions. Although this encompasses medical management of symptoms and a burdened body, the 'self' should not be reduced to a 'disease manager'. More consideration of nonmedical issues as self-reliance, autonomy and social participation in clinical practice is needed to improve the quality of paediatric care, and the quality of life of young people with chronic kidney failure (Annunziato et al. 2012). The SGU-N that translates the broad definition of self-management into nine specific life areas, seems to be a promising tool allowing professionals in paediatric nephrology to widen their focus.

\section{Self-Management: Weighing Up Costs And Benefits}

Goal setting by participants appeared to be limited. They might find it hard to actually formulate goals to work with, or to change their role during consultation. 
Sattoe, J.N.T. 'Skills for growing up': supporting autonomy in young people with kidney disease. Journal of Renal Care: 2014, 40(2), 131-139

The tool demands an active role of young people and parents and assigns a more passive demand-driven role to professionals. Young people and parents now need to explicitly set (a part of) the agenda; they may have to adjust to this new responsibility.

Professionals did not perceive the lack of action plans as problematic, it allowed them to pro-actively support adolescents and their parents in their goal setting, which they viewed as an important task in using the SGU-N. This should not be a problem as long as professionals do not entirely take over the agenda setting. Yet, some professionals wanted to see the whole list, even if an action plan was presented, and explicitly wished to use it to test patients' knowledge and competencies. These professionals might have a natural tendency to take over responsibility of their patients. However, telling young people what they should do is not a viable option (Glasgow et al.2003). Moreover, developing self-management and becoming autonomous does not imply that adolescents will do what is considered right from a medical perspective.

Young people with ESKD are known to weigh medical advantages against social disadvantages (Nicholas et al. 2011; Wells et al. 2012). This weighing is a normal task of adolescence that should be acknowledged (Curtis-Tyler 2010). Noncompliance is often viewed as 'indirect self-destructive behaviour' or 'diseasesustaining behaviour' in clinical practice and negatively attributed to youths, while in fact they feel the need to talk about their motivation for their behaviour (Wolff et al. 1998; Waters 2008). Themes as 'living a normal life' and 'independence' strongly relate to young people's decision making (Mitchell 2012). Training in knowledge and competencies is necessary, but not enough to understand and support selfmanagement. Professionals should gain insight into young people's lived experiences in acquiring autonomy and social participation and identify challenging areas - as these will affect their self-management (Glasgow et al. 2003; Snethen et al. 2004; Schulman-Green et al. 2012; Walker \& Buchbinder 2012; Reid et al. 2013). The SGU-N allows professionals to address different life areas, and its use might for instance be complemented with motivational interviewing (Naar-King \& Suarez 2010) to deeper the insight in these life areas, and to support adolescents in formulating their goals and action plans. In this way, professionals guide adolescents in their transition to independence.

\section{Strengths And Limitations}

Our study included all paediatric nephrology centres in the Netherlands, and the sample of patients was heterogeneous in terms of age. The response rates were fairly good. Furthermore, the KLIK PROfile allows for good monitoring of patient reported outcomes (Haverman et al. 2013), and integration of the SGU-N in this system seems promising. However, the effectiveness of the instrument on adolescents is not considered. Neither are the participants' views on the SGU-N. Hilberink et al. (2013) conducted a pre-post-evaluation. Unfortunately, our small pilot sample did not allow for such approach. Since the instrument is for young people with ESKD and their parents, and patients' view are important considerations in research with young people (van Staa et al. 2011b; Darbyshire et al. 2005), an essential recommendation for future research is to evaluate its effectiveness. 
Sattoe, J.N.T. 'Skills for growing up': supporting autonomy in young people with kidney disease. Journal of Renal Care: 2014, 40(2), 131-139

\section{Implications For Practice}

The SGU-N is a promising tool for professionals in paediatric nephrology. A webbased application is considered to increase the feasibility within daily practice. The tool can help young people achieving autonomy and may contribute to their successful transition to adulthood and adult care.

\section{CONCLUSION}

The SGU-N was developed in a participative way to encourage normal development towards autonomy. Young people, parents, professionals and experts reached consensus on the broad scope life areas, including both social participation and medical management of ESRD. Professionals applied and appreciated the instrument, but having it available online is important for the instrument's feasibility. Furthermore, they have to get used to this new working method, and are hesitant about a more passive role transferring responsibility to young people and parents. The challenge for professionals in paediatric nephrology is to move beyond the focus on medical management and to consider young people's developmental tasks when coaching them into adulthood. Insight into their lived experiences is essential for good self-management support.

\section{Acknowledgements}

The authors want to thank Andrea Blok, Daniella Kramp, Lisette van Sinttruije and Evelien Polderman (Rotterdam University for Applied Sciences) for their help in data collection. Furthermore, we thank young people and their parents, and the professionals of the participating centres. Also, we are grateful to the expert group, especially the people who were involved in the development of the original Dutch tool: Karel Maathuis (University Medical Centers Groningen), Marij Roebroeck (Erasmus Medical Center Rotterdam) and Ieteke Vos (Rehabilitation Center Blixembosch Eindhoven). Next, we thank the Holland Bloorview Kids Rehabilitation Hospital in Toronto for allowing us to use the original SGU tool. Finally, we thank Lotte Haverman and Hedy van Oers (Emma Children's Hospital AMC) and Olivier Blanson Henkemans (TNO) for their efforts in exploring the integration of the SGU$\mathrm{N}$ into the KLIK PROfile.

\section{Conflict Of Interest}

No conflict of interest has been declared by the authors.

\section{Author Contributions}

JNTS: Participated in design and coordination, undertook Delphi study, interviews and focus groups, analysed the data, drafted the manuscript, read and approved the final manuscript. SRH: Participated in design and coordination, analysed the data, helped to draft the manuscript, read and approved the final manuscript. MACP: Assisted in data collection and analysis, read and approved the final manuscript. ALVS: Principal Project Leader, conceived the study, participated in design and coordination, read and approved the final manuscript.

\section{Biography}

Jane N.T. Sattoe is a $\mathrm{PhD}$ candidate. She is affiliated to Rotterdam University (Center of Expertise Innovations in Care) and Erasmus University Rotterdam (Institute of Health Policy \& Management) in Rotterdam, the Netherlands. Her PhD research focuses on self-management of young people with chronic conditions. 
Sattoe, J.N.T. 'Skills for growing up': supporting autonomy in young people with kidney disease. Journal of Renal Care: 2014, 40(2), 131-139

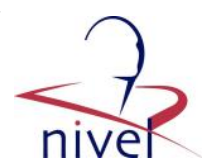

\section{Ancillary}

\section{REFERENCES}

Annunziato R.A., Jerson B., Seidel J. et al. (2012). The psychosocial challenges of solid organ transplant recipients during childhood. Pediatric Transplantation 16, 803-811.

Barlow J., Wright C., Sheasby J. et al. (2002). Self-management approaches for people with chronic conditions: a review. Patient Education and Counseling 48, 177-187.

Creswell J.W. (2003). Research Design: Qualitative, Quantitative and Mixed Methods. London: Sage.

Curtis-Tyler K. (2010). Levers and barriers to patient-centred care with children: findings from a synthesis of studies of the experiences of children living with type 1 diabetes or asthma. Child: Care, Health and Development 37, 540-550.

Darbyshire P., Oster C. \& Hennings P. (2005). Children's and young people's experiences of chronic renal disease: a review of the literature, methodological commentary and a alternative proposal. Journal of Clinical Nursing 15, 751-760.

Gall C., Kingsnorth S. \& Healy H. (2006). Growing up ready: a shared management approach. Physical and Occupational Therapy in Pediatrics 26, 47-62.

Glasgow R.E., Davis C.L., Funnell M.M. et al. (2003). Implementing practical interventions to support chronic illness self-management. Joint Commission Journal on Quality and Patient Safety 29, 563-574.

Goffman E. (1963). Stigma: Notes on the Management of Spoiled Identity. Englewood Cliffs, NJ: Prentice Hall.

Grootenhuis M.A., Stam H., Last B.F. et al. (2006). The impact of delayed development on the quality of life of adults with end-stage renal disease since childhood. Pediatric Nephrology 21, 538-544.

PubMed |

Web of Science® Times Cited: 17 |

Groothoff J.W., Grootenhuis M.A., Offringa M. et al. (2005). Social consequences in adult life of end-stage renal disease in childhood. Journal of Pediatrics 146, 512-517.

Guidelines for Service Providers. (2007). Supporting youth \& families in using the skills for growing up checklists [Internet]. Guidelines for Service Providers-Bloorview Kids Rehab [cited 2012 June 25].

https://secure1.securewebexchange.com/bloorview.ca/resourcecentre/familyresourcef/doc uments/serviceproviderguidelines.pdf (accessed 13 June 2011).

Haverman L., Engelen V., Van Rossum M.A. et al. (2011). Monitoring health-related quality of life in paediatric practice: development of an innovative web-based application. BMC Pediatrics 11, 3.

Haverman L., Verhoof E.J., Maurice-Stam H. et al. (2012). Health-related quality of life and psychosocial developmental trajectory in young female beneficiaries with JIA. Rheumatology (Oxford) 51, 368-374.

Haverman L., Van Rossum M.A., Van Veenendaal M. et al. (2013). Effectiveness of a webbased application to monitor health-related quality of life. Pediatrics 131, e533-e543.

Icard P.F., Hower S.J., Kuchenreuther A.R. et al. (2008). The transition from childhood to adulthood with ESRD: educational and social challenges. Clinical Nephrology 69, 1-7.

Jansen D.L., Heijmans M., Rijken M. et al. (2010). The development of and first experiences with a behavioural self-regulation intervention for end-stage renal disease patients and their partners. Journal of Health Psychology 16, 274-283.

Jones J. \& Hunter D. (1995). Consensus methods for medical and health services research. BMJ 311, 376-380.

Kieckhefer G.M. (2002). A shared management approach to transition. Paper presented at the Hospital for Sick Children, Toronto, ON.

Koch T., Jenkin P. \& Kralik D. (2004). Chronic illness self-management: locating the 'self'. Journal of Advanced Nursing 48, 484-492.

Lorig K.R. \& Holman H. (2003). Self-management education: history, definition, outcomes, and mechanisms. Annals of Behavioral Medicine 26, 1-7. 
Sattoe, J.N.T. 'Skills for growing up': supporting autonomy in young people with kidney disease. Journal of Renal Care: 2014, 40(2), 131-139

Maathuis C.G.B., Vos I., Roebroeck M.E. et al. (2012). Een instrument om vaardigheden voor zelfstandigheid te vergroten. De Groei-wijzer. [A tool to enhance skills for selfreliance. The Skills for Growing Up.] Nederlands Tijdschrift voor Revalidatiegeneeskunde [Dutch Journal of Rehabilitation medicine] 3, 115-119.

Martinez W., Carter J.S. \& Legato L.J. (2011). Social competence in children with chronic illness: a meta-analytic review. Journal of Pediatric Psychology 36, 878-890.

Maurice-Stam H., Verhoof E.J., Caron H.N. et al. (2011). Are survivors of childhood cancer with an unfavourable psychosocial developmental trajectory more likely to apply for disability benefits? Psychooncology 22, 708-714.

McDonagh J.E. (2000). Child-adult interface. The adolescent challenge. Nephrology Dialysis Transplantation 15, 1761-1765.

Meijer S.A., Sinnema G., Bijstra J.O. et al. (2002). Coping styles and locus of control as predictors for psychological adjustment of adolescents with a chronic illness. Social Science and Medicine 54, 1453-1461.

Mitchell W.A. (2012). Making choices about medical interventions: the experience of disabled young people with degenerative conditions. Health Expectations. doi: 10.1111/j.1369-7625.2011.00752.x.

Modi A.C., Pai A.L., Hommel K.A. et al. (2012). Pediatric self-management: a framework for research, practice, and policy. Pediatrics 129, e473-e485.

Naar-King S. \& Suarez M. (2010). Motivational Interviewing with Adolescents and Young Adults. New York: The Guilford Press.

Newman S., Steed L. \& Mulligan K. (2009). Chronic Physical Illness: Self-Management and Behavioural Interventions. New York: Open University Press.

Nicholas D.B., Picone G. \& Selkirk E.K. (2011). The lived experiences of children and adolescents with end-stage renal disease. Qualitative Health Research 21, 162-173.

Reid J., Noble H.R., Porter S. et al. (2013). A literature review of end-stage renal disease and cachexia: understanding experience to inform evidence-based healthcare. Journal of Renal Care 39, 47-51.

Schipper K. \& Abma T.A. (2011). Coping, family and mastery: top priorities for social science research by patients with chronic kidney disease. Nephrology Dialysis Transplantation 26 , 3189-3195.

Schulman-Green D., Jaser S., Martin F. et al. (2012). Processes of self-management in chronic illness. Journal of Nursing Scholarship 44, 136-144.

Snethen J.A., Broome M.E., Kelber S. et al. (2004). Coping strategies utilized by adolescents with end stage renal disease. Nephrology Nursing Journal 31, 41-49.

Stam H., Hartman E.E., Deurloo J.A. et al. (2006). Young adult patients with a history of pediatric disease: impact on course of life and transition into adulthood. Journal of Adolescent Health 39, 4-13.

Turkel S. \& Pao M. (2007). Late consequences of chronic pediatric illness. Psychiatric Clinics of North America 30, 819-835.

Van Staa A.L., Van der Stege H.A., Jedeloo S. et al. (2011a). Readiness to transfer to adult care of adolescents with chronic conditions: exploration of associated factors. Journal of Adolescent Health 48, 295-302.

Van Staa A.L., Jedeloo S., Van Meeteren J. et al. (2011b). Crossing the transition chasm: experiences and recommendations for improving transitional care of young adults, parents and providers. Child: Care, Health and Development 37, 821-832.

Verhoof E., Maurice-Stam H., Heymans H. et al. (2011). Growing into disability benefits? Psychosocial course of life of young adults with a chronic somatic disease or disability. Acta Paediatrica 101, e19-e26.

Walker R.G. \& Buchbinder R. (2012). Fostering the ability of patients to self-manage their CKD. Nephrology Dialysis Transplantation 27, 3680-3682.

Waters A.L. (2008). An ethnography of a children's renal unit: experiences of children and young people with long-term renal illness. Journal of Clinical Nursing 17, 3103-3114.

Wells F., Ritchie D. \& McPherson A.C. (2012). 'It is life threatening but I don't mind'. A qualitative study using photo elicitation interviews to explore adolescents' experiences of renal replacement therapies. Child: Care, Health and Development 39, 602-612.

Wolff G., Strecker K., Vester U. et al. (1998). Non-compliance following renal transplantation in children and adolescents. Pediatric Nephrology 12, 703-708. 


\section{BOX FIGURES EN TABLES}

\section{Box 1. Item examples and action plan format}

- ME

- 'I can tell others what my condition is and what it practically means for my daily life' $\left(12-16\right.$ yrs $\left.^{*}\right)$

- HEALTHCARE

- 'I know what to do when I forget to take my medication' (12-16 yrs)

- RELATIONSHIPS

- 'I spend time with my friends outside school' (12-16 yrs)

- EDUCATION

- 'I know what to do to get an internship' (17+ yrs)

- WORK

- 'I know the influence of my condition on work' (17+ yrs)

- LIVING AND ADL

- 'I sometimes do chores at home' (7-11 yrs)

- TRANSPORTATION

- 'I travel by myself by public transportation' (17+ yrs)

- LEISURE ACTIVITIES

- 'I attend a camp, like school camp or soccer camp' (7-11 yrs)

- SPORTS

- 'I can swim' (7-11 yrs)

- ACTION PLAN

- Step 1: I want to work on the following items: [items scored with no]

- Step 2: I will take the following steps to work on these items: [description of steps to take]

- Step 3: I will work on these items on: [description of step] [date]

- $\quad$ *yrs, years.

Table 1. Participants' characteristics

\begin{tabular}{|c|c|c|}
\hline \begin{tabular}{|l|} 
Paediatric \\
nephrology \\
centre
\end{tabular} & Role & Gender \\
\hline \multicolumn{3}{|c|}{ 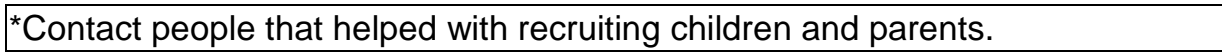 } \\
\hline \multirow{10}{*}{1} & Paediatric nurse* & Female \\
\hline & Social worker & Male \\
\hline & Nephrologist & Female \\
\hline & Psychologist & Female \\
\hline & Educational consultant & Female \\
\hline & Pedagogue & Female \\
\hline & Child aged $12-16$ years & Male \\
\hline & Child aged $17+$ years & Male \\
\hline & Parent of child aged $\leq 12$ years & Female \\
\hline & Parent of child aged $\geq 13$ years & Female \\
\hline
\end{tabular}




\begin{tabular}{|c|c|c|}
\hline \begin{tabular}{|l} 
Paediatric \\
nephrology
\end{tabular} & Role & Gender \\
\hline \multirow{9}{*}{2} & Nurse specialist_ & Female \\
\hline & Nephrologist (adult care) & Male \\
\hline & Nephrologist & Female \\
\hline & Psychologist & Female \\
\hline & Social worker & Male \\
\hline & Child aged $12-16$ years & Male \\
\hline & Child aged $17+$ years & Female \\
\hline & Parent of child aged $\leq 12$ years & Female \\
\hline & Parent of child aged $\geq 13$ years & Female \\
\hline \multirow{9}{*}{3} & Nurse specialist_ & Female \\
\hline & Specialised nurse & Female \\
\hline & Dietitian & Female \\
\hline & Psychologist & Female \\
\hline & Nephrologist & Male \\
\hline & Child aged $12-16$ years & Male \\
\hline & Child aged $17+$ years & Female \\
\hline & Parent of child aged $\leq 12$ years & Female \\
\hline & Parent of child aged $\geq 13$ years & Female \\
\hline \multirow{9}{*}{4} & Nurse practitioner_ & Female \\
\hline & Nephrologist & Female \\
\hline & Social worker & Female \\
\hline & Psychologist & Female \\
\hline & Nurse & Female \\
\hline & Child aged $12-16$ years & Male \\
\hline & Child aged $17+$ years & Female \\
\hline & Parent of child aged $\leq 12$ years & Female \\
\hline & Parent of child aged $\geq 13$ years & Female \\
\hline \multirow{10}{*}{5} & Nurse specialist__ & Female \\
\hline & Nephrologist & Male \\
\hline & Educationalist & Female \\
\hline & Social worker (adult care) & Female \\
\hline & Social worker & Female \\
\hline & Nurse (dialysis) & Female \\
\hline & Child aged $12-16$ years & Male \\
\hline & Child aged $17+$ years & Female \\
\hline & Parent of child aged $\leq 12$ years & Female \\
\hline & Parent of child aged $\geq 13$ years & Female \\
\hline
\end{tabular}


Sattoe, J.N.T. 'Skills for growing up': supporting autonomy in young people with kidney

disease. Journal of Renal Care: 2014, 40(2), 131-139

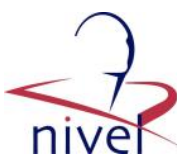

Table 2. Comparison of the distribution of items within the SGU, pilot SGU-N and final SGU-

$\mathrm{N}$

\begin{tabular}{|c|c|c|c|c|c|c|c|c|c|}
\hline \multirow[b]{2}{*}{ Life areas } & \multicolumn{3}{|c|}{ Getting started, $\mathbf{n}(\%)_{-}^{\star}$} & \multicolumn{3}{|c|}{ On my way, n (\%)_ } & \multicolumn{3}{|c|}{ Almost there, n (\%)* } \\
\hline & SGU & Pilot SGU-N & \begin{tabular}{|l|} 
Final \\
SGU- \\
N
\end{tabular} & SGU & \begin{tabular}{||l} 
Pilot \\
SGU \\
$-N$
\end{tabular} & \begin{tabular}{|l|} 
Final \\
SGU \\
$-\mathrm{N}$ \\
\end{tabular} & SGU & \begin{tabular}{|l} 
Pilot \\
SGU \\
$-N$
\end{tabular} & $\mid \begin{array}{l}\text { Final } \\
\text { SGU-N }\end{array}$ \\
\hline \multicolumn{10}{|c|}{${ }^{\star}$ Number of items (\% items compared to total in all life areas). } \\
\hline $\mathrm{Me}$ & $6(15)$ & $\mid 5(10)$ & $6(14)$ & $6(10)$ & $\begin{array}{l}10 \\
(11)\end{array}$ & \begin{tabular}{|l|}
10 \\
$(13)$ \\
\end{tabular} & 5 & $\begin{array}{l}10 \\
(12)\end{array}$ & $10(14)$ \\
\hline Living & $15(37)$ & $11(23)$ & $9(21)$ & $12(20)$ & $8(9)$ & $7(9)$ & $\begin{array}{r}7 \\
(14)\end{array}$ & $7(8)$ & || $7(10)$ \\
\hline Relationships & $3(7)$ & $2(4)$ & $4(10)$ & $10(17)$ & $\begin{array}{l}11 \\
(12)\end{array}$ & \begin{tabular}{|l|}
10 \\
$(13)$ \\
\end{tabular} & $\begin{array}{c}10 \\
(20) \\
\end{array}$ & $\begin{array}{l}14 \\
(17)\end{array}$ & $15(21)$ \\
\hline Education & $3(7)$ & $3(6)$ & $3(7)$ & $8(14)$ & $9(10)$ & $8(10)$ & $3(6)$ & $4(5)$ & $4(6)$ \\
\hline Transportation & $2(5)$ & $2(4)$ & $2(5)$ & $3(5)$ & $2(2)$ & $2(3)$ & $2(4)$ & $2(2)$ & $2(3)$ \\
\hline Sports & $3(7)$ & $3(6)$ & $3(7)$ & $2(3)$ & $2(2)$ & $2(3)$ & $2(4)$ & $2(2)$ & $2(3)$ \\
\hline Leisure & $2(5)$ & $3(6)$ & $3(7)$ & $5(8)$ & $8(9)$ & $9(11)$ & $4(8)$ & $5(6)$ & $4(6)$ \\
\hline Work & |- & |- & - & $1(2)$ & $1(1)$ & $1(1)$ & \begin{tabular}{|l|}
6 \\
$(12)$ \\
\end{tabular} & $5(6)$ & (5 (7) \\
\hline Health care & $7(17)$ & $19(40)$ & $12(29)$ & $12(20)$ & $\begin{array}{l}40 \\
(44)\end{array}$ & \begin{tabular}{|l|}
29 \\
$(37)$
\end{tabular} & $\begin{array}{r}11 \\
(22)\end{array}$ & $\begin{array}{c}34 \\
(41)\end{array}$ & $21(30)$ \\
\hline
\end{tabular}

